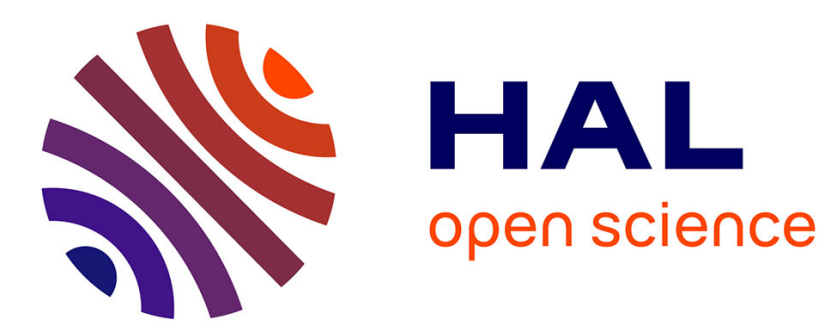

\title{
Direct evidence of defect mobility in the incommensurate phase of $[\mathrm{N}(\mathrm{CD} 3) 4] 2 \mathrm{ZnCl} 4$ crystals
}

M. Ribet

\section{To cite this version:}

M. Ribet. Direct evidence of defect mobility in the incommensurate phase of [N(CD3)4]2ZnCl4 crystals. Journal de Physique Lettres, 1983, 44 (23), pp.963-970. 10.1051/jphyslet:019830044023096300 . jpa-00232288

\section{HAL Id: jpa-00232288 https://hal.science/jpa-00232288}

Submitted on 1 Jan 1983

HAL is a multi-disciplinary open access archive for the deposit and dissemination of scientific research documents, whether they are published or not. The documents may come from teaching and research institutions in France or abroad, or from public or private research centers.
L'archive ouverte pluridisciplinaire HAL, est destinée au dépôt et à la diffusion de documents scientifiques de niveau recherche, publiés ou non, émanant des établissements d'enseignement et de recherche français ou étrangers, des laboratoires publics ou privés. 


\title{
Direct evidence of defect mobility in the incommensurate phase of $\left[\mathrm{N}\left(\mathrm{CD}_{3}\right)_{4}\right]_{2} \mathrm{ZnCl}_{4}$ crystals
}

\author{
M. Ribet \\ Groupe de Dynamique des Phases Condensées, Université des Sciences et Techniques du Languedoc, \\ Place E. Bataillon, 34060 Montpellier Cedex, France
}

(Reçu le 31 mai 1983, révisé le 5 septembre, accepté le 5 octobre 1983)

\begin{abstract}
Résumé. - Des topographies $\mathrm{X}$ en transmission faites durant des cycles thermiques allant de la phase paraélectrique à la transition de blocage sur des cristaux de $\left[\mathrm{N}\left(\mathrm{CD}_{3}\right)_{4}\right]_{2} \mathrm{ZnCl}_{4}$ de très bonne qualité cristalline ont montré (i) une précipitation de défauts au voisinage de la transition de blocage et (ii) des contrastes pseudo-périodiques qui disparaissent dans la phase paraélectrique.
\end{abstract}

\begin{abstract}
X-ray transmission topographies made during thermal cycles from the paraelectric phase to the lock-in transition temperature on $\left[\mathrm{N}\left(\mathrm{CD}_{3}\right)_{4}\right]_{2} \mathrm{ZnCl}_{4}$ crystals of very good crystalline quality have shown (i) a precipitation of defects near the lock-in transition and (ii) pseudo-periodic contrasts which disappear in the paraelectric phase.
\end{abstract}

\section{Introduction.}

In incommensurate insulating systems, defects have recently been suspected of being at the origin of several anomalies : thermal hysteresis observed on the variation curve of the dielectric constant [1], memory effect or relaxation effects [2,3] showing the importance of the history of the -sample and of the speed at which temperature or pressure have previously varied in the incommensurate phase; and, absence of lock-in transition related to stoichiometric deviation having its origin in growth conditions [4].

The models already proposed to account for the action of defects in incommensurate phases involve either the pinning of discommensurations by the defects which hinder the crystal from reaching thermal equilibrium [1]; or, the mobility of defects carried by discommensurations [2, 3]. The concentration of defects would be, in the latter case, modulated with the same period as that of the crystal modulation and, therefore, any change in the modulation period would produce a small migration of defects [2].

However, up to now, no direct observation of the behaviour of point defects or dislocations in incommensurate phases has been reported.

In this paper, we describe experimental results obtained by X-ray transmission topographies, giving direct evidence of the alteration of the defect configuration in the incommensurate phase and of the defect mobility near the lock-in transition. 
This study has been performed on $\left[\mathrm{N}\left(\mathrm{CD}_{3}\right)_{4}\right]_{2} \mathrm{ZnCl}_{4}$ crystals, which, among the incommensurate insulators of the $\mathrm{K}_{2} \mathrm{SeO}_{4}$ family, have a peculiar behaviour [5]. Their high temperature phase is not polar, orthorhombic, with the space group Pnma $(a=12.276, b=8.991, c=15.526$; number of molecules per unit cell, $Z=4$ ). At $T_{\mathrm{i}}=25^{\circ} \mathrm{C}$ they undergo a second order transition into an incommensurate phase characterized by a modulation wave vector $k_{i}=q a^{*}$ which varies slightly with temperature $\left(q=0.428\right.$ at $\left.T_{\mathrm{i}}\right)$. At $T_{\mathrm{c}}=6^{\circ} \mathrm{C}$ there appears, on a small temperature range, a lock-in at the commensurate value of $3 / 7$ before a commensurate ferroelastic phase which takes place at $4.5^{\circ} \mathrm{C}$ with $k=1 / 2 a^{*}(Z=8)$ followed at $-1.4{ }^{\circ} \mathrm{C}$ by another transition with $k=1 / 3 a^{*}(Z=12)$. The ferroelectric lock-in phase characterized by a wave vector $k=0.4 a^{*}$ which appears in the hydrogenated compound, is observed in the deuterated one only under pressure [6].

\section{Experiment.}

The starting material was synthetized in the laboratory by reaction between $\mathrm{CD}_{3} \mathrm{OD}$ and $\mathrm{NH}_{4} \mathrm{Cl}$ at $200^{\circ} \mathrm{C}$ in an autoclave and then purified in butylic alcohol.

Large single crystals $\left(2\right.$ to $3 \mathrm{~cm}^{3}$ ) of very good crystalline quality were grown by the decreasing temperature method from supersaturated $\mathrm{D}_{2} \mathrm{O}$ solutions with $\mathrm{ZnCl}_{2}$ and $\mathrm{N}\left(\mathrm{CD}_{3}\right)_{4} \mathrm{Cl}$ with stoichiometric proportions.

X-ray transmission topographies [7] were performed with a conventional Lang camera fitted with a temperature cell in order to follow the behaviour of defects in the incommensurate phase.

This cell operates with 2 Peltier thermoelements (CAMBION) $\left(31.8 \times 31.8 \times 3.8 \mathrm{~mm}^{3}\right)$ situated on a heat water sink.

The sample is held on a $1 / 10 \mathrm{~mm}$ thick aluminium sheet tightened on the cold face of the thermoelements.

To prevent it from ambient humidity, the sample is enclosed in a mylar air-tightness cell filled with nitrogen.

The resolution of the setting is very slightly changed because the small size of the cell in the incident beam direction ( $20 \mathrm{~mm}$ including all protections from ambient atmosphere) allows us to keep a film-sample distance which does not exceed $12 \mathrm{~mm}$.

The thermal stability of the device is about $\pm 0.2^{\circ} \mathrm{C}$. The temperature may be quickly set in the range $30^{\circ} \mathrm{C}$ to $0^{\circ} \mathrm{C}$.

The temperature is probed by means of a chromel-alumel thermocouple situated on the sample. This measurement is only used to provide a relative scale. The actual temperature is known by the position of a satellite reflection.

The samples used for X-ray observations are (001) slices cut out from several crystals. Their thickness is about $1 \mathrm{~mm}$ so that $\mu t=2, \mu$ being the linear absorption coefficient for MoK $\alpha$ and $t$ being the crystal thickness.

Experiments were performed beginning at room temperature and doing successive steps for every degree in the range $20^{\circ} \mathrm{C}-11^{\circ} \mathrm{C}$ and very half degree in the range $11^{\circ} \mathrm{C}-5^{\circ} \mathrm{C}$. Each topography lasts 24 or 48 hours.

\section{Results.}

3.1 Alteration OF DEFECT CONFIGURATION. - The main results are summarized on the three topographs of figures $1 a-b-c$ which are 020 reflections, all three performed at room temperature. The arrow $g$ gives the direction of the diffraction vector.

Figure $1 a$ is a topograph performed before any thermal cycle. Two bunches of dislocations « D », one in the centre and the other at the left hand side of the topograph are the main features. These dislocations are elongated in the [100] direction and their Burgers vector is parallel to the [010] direction. They show the characteristic double contrast of dislocations parallel to the 
surface on translation topographies [8] (the width of the rocking curve for the 020 reflection is 2.8"). Several equal deformation fringes [9] $\mathrm{F}^{\prime \prime}$ caused by the central dislocation bunch are visible (the extinction distance of X-rays in this case is $122 \mu \mathrm{m}$ ).

One solid inclusion is visible at the right hand side. Other defects are surface defects.

After a step of 24 hours at a temperature slightly above the lock-in transition temperature, $T_{\mathrm{c}}=6^{\circ} \mathrm{C}$, the appearance of the sample is greatly modified (Fig. 1b).

The following features can be noted :

- precipitation of defects giving a contrast with either two lobes or four lobes with, in both
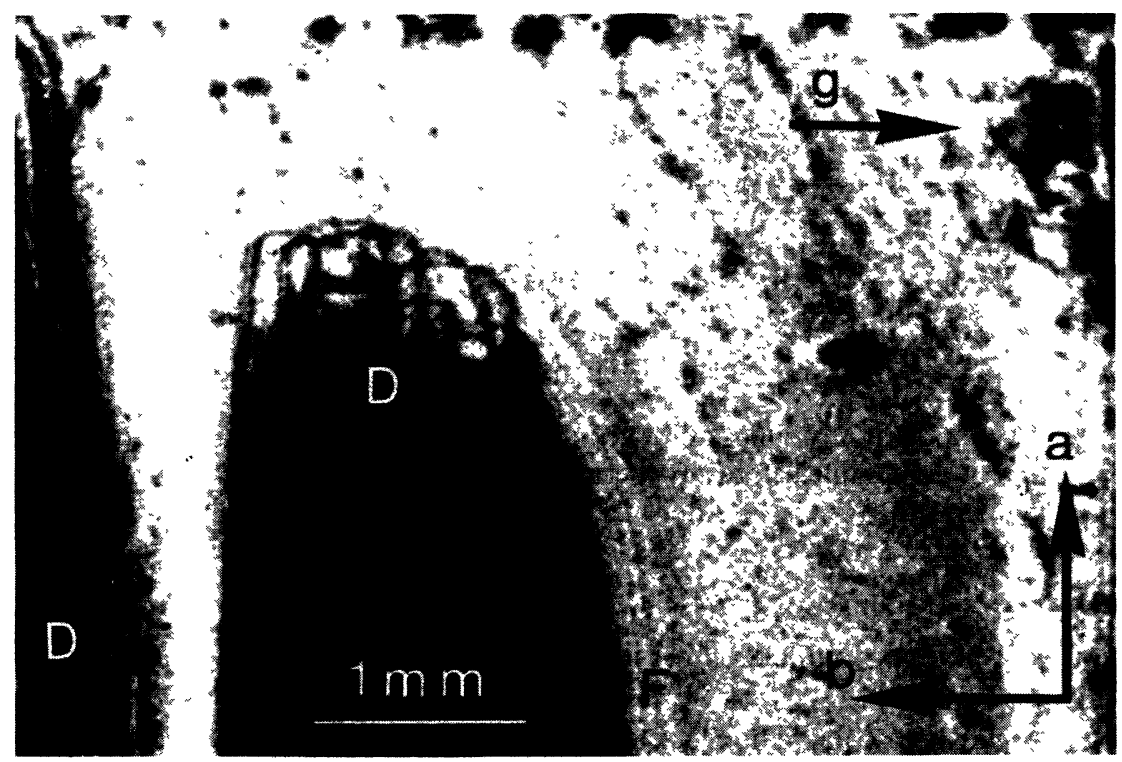

Fig. 1a)

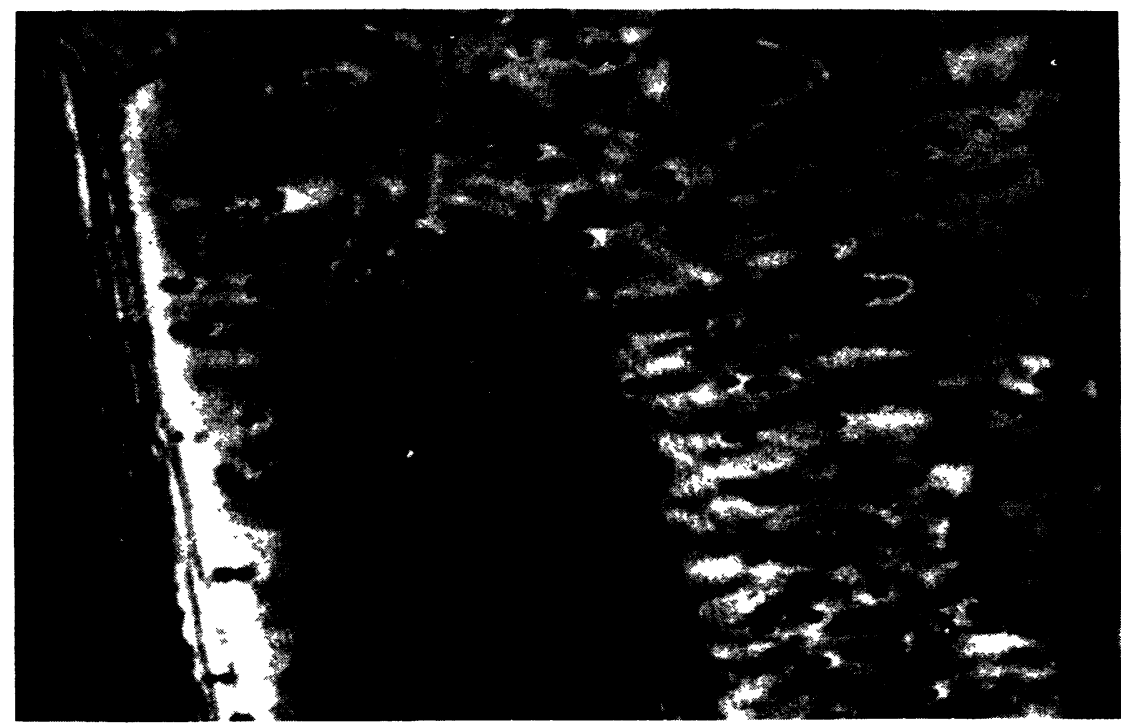

Fig. $1 b$ ) 


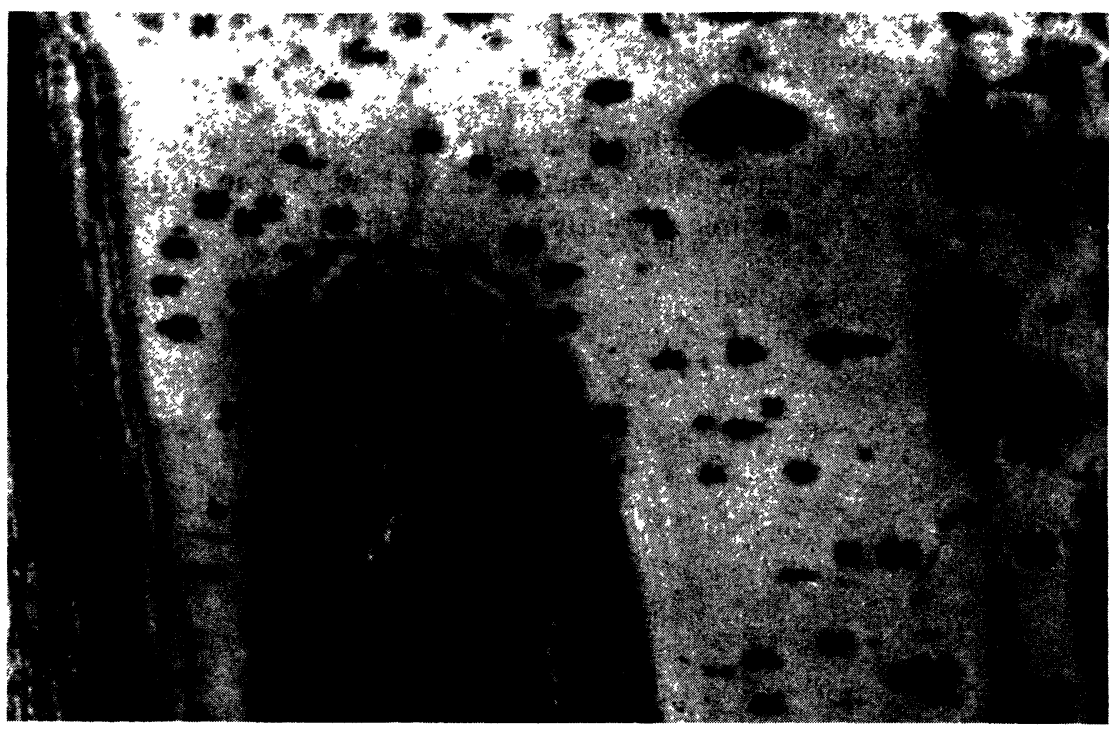

Fig. 1c)

Fig. 1. - Lang X-ray topograph of a (001) slice of $\left[\mathrm{N}\left(\mathrm{CD}_{3}\right)_{4}\right]_{2} \mathrm{ZnCl}_{4}$ crystal, 020 reflection. Room temperature. a) Topograph of the sample before any thermal cycle; $b$ ) After a 24 hours step at a temperature just above the lock-in temperatures $\left.\left(6^{\circ} \mathrm{C}\right) ; c\right)$ After a 24 hours step at a temperature higher than the paraelectric transition temperature.

cases, a no contrast line perpendicular to the diffraction vector $\mathbf{g}$. These defects are scattered at random in the crystal,

- decoration of dislocations. Their contrast is largely modified. This is especially visible on the curled part of the dislocations at the centre of the photograph,

- long distance strains making waves with weak contrast; their direction is not away from the [010] direction. These strains interact with equal deformation fringes which become slightly winding.

After a new 24 hours step at a temperature higher than $T_{i}$, the long range strains disappear but the other defects remain (Fig. 1c). At the right hand side, some large defects appear, due to a layer of liquid inclusions which increased during the heating process of the sample.

3. 2 DEFECT MOBILITY. - Figures $2 a-d$ show a selection of topographs taken during a thermal cycle from $T_{\mathrm{i}}$ to $T_{\mathrm{c}}$.

An almost perfect sample of $8 \times 8 \mathrm{~mm}^{2}$ has been selected in a (001) slice (Fig. $2 a$ ).

From a temperature of about $8.3^{\circ} \mathrm{C}$ onwards, defect contrasts of two kinds (two lobes and four lobes) progressively appear and grow (Fig. $2 b$ ) (the large grey defect at the centre of the topograph is surface damage caused when the crystal was introduced in the cell). At the same time, weak contrasts appear, their direction being about the [010] direction and strains (black contrasts) are spread over a large part of the crystal.

At a temperature of $6.5^{\circ} \mathrm{C}$ new features may be noticed (Fig. $2 c$ ) :

- small lines perpendicular to the [100] direction (which is the modulation direction). They are visible in the strained parts of the crystal,

- diffusions parallel to the [100] direction. The contrasts previously created are elongated in this direction. Let us notice the four lobe defect at the lower part of the photograph : its contrast develops as two wings elongated in the [100] direction. 
At last when, from figure $2 c$ configuration, the sample is quickly brought to room temperature, a kind of freezing of defects is produced though the temperature is raised and not lowered (Fig. $2 d$ ).

The topograph shows lines of defects exactly in the [100] direction, starting on larger defects and terminated in thin lines.

\section{Discussion.}

We can classify the observed contrasts as being of three kinds :

- contrasts perpendicular to the modulation direction,

- precipitation of local defects,

- diffusion lines parallel to the modulation direction.

The three types of contrast appear simultaneously.

The first kind of observed contrast is made of small lines perpendicular to the modulation direction; on cooling, they appear at about $7^{\circ} \mathrm{C}$ and disappear in the lock-in phase at $T_{\mathrm{c}}=6^{\circ} \mathrm{C}$. At first they are fuzzy, then they become sharper in the strained parts of the sample, but remain fuzzy in almost perfect ones. Their distance is estimated to be of the order of few $\mu \mathrm{m}$.

These small lines which appear only in the temperature range of $7^{\circ} \mathrm{C}-6^{\circ} \mathrm{C}$, just above the lockin transition temperature, have a very weak activation energy and cannot be lattice defects in the classical sense (dislocations, point defects, ...).

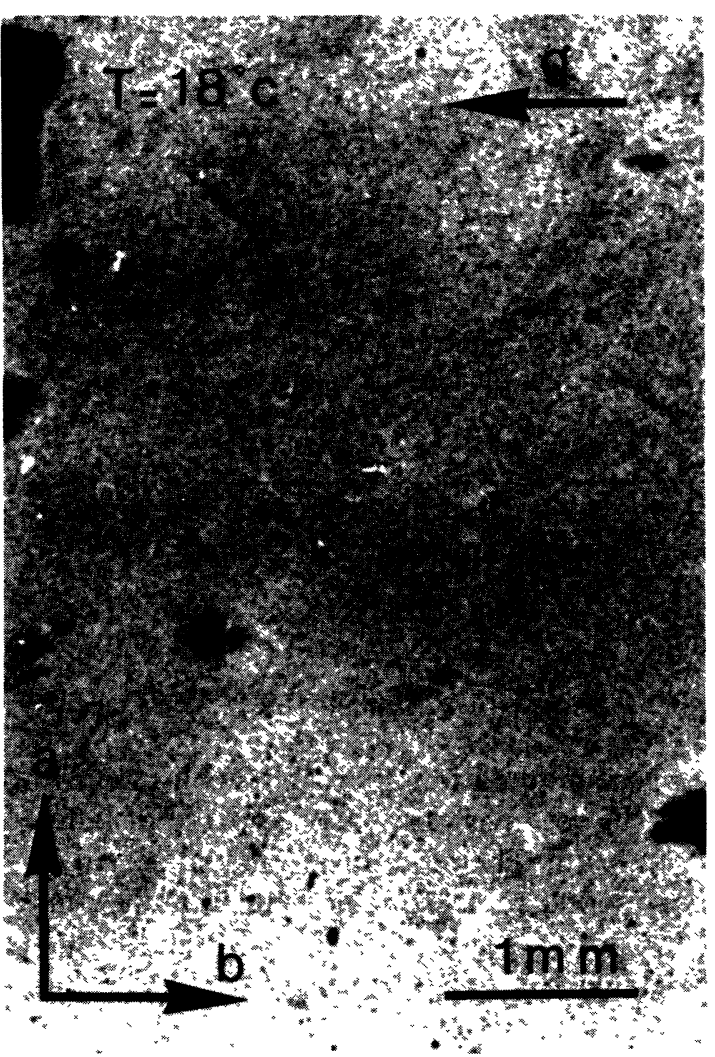

Fig. $2 a$ )

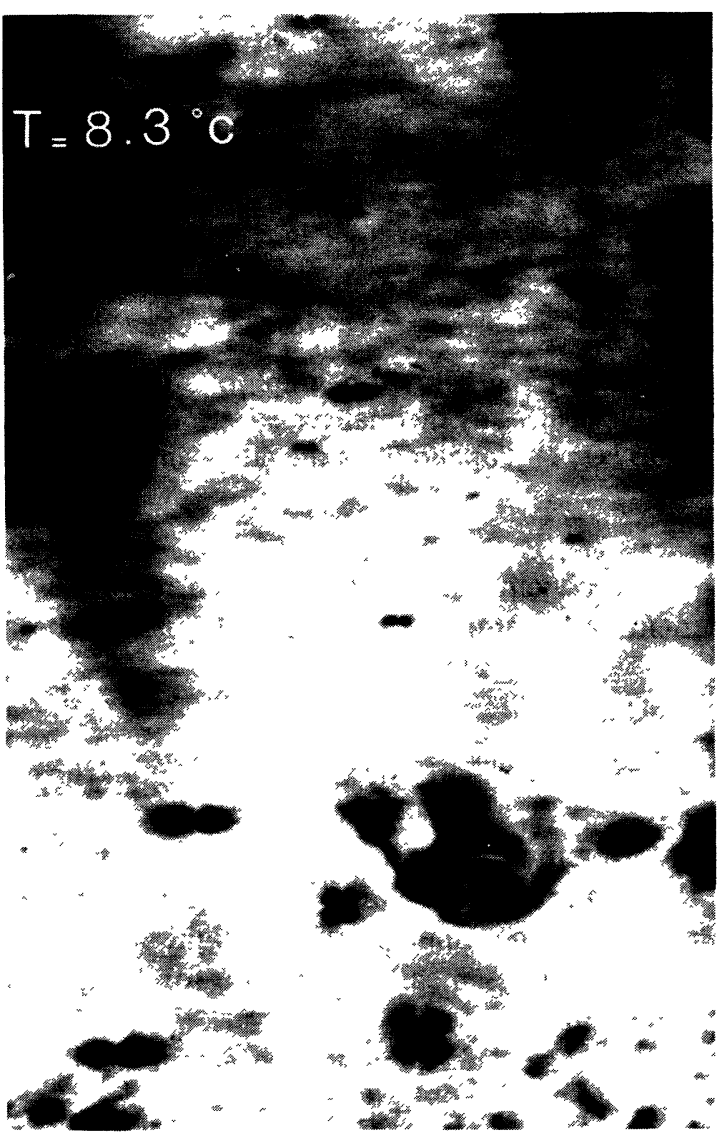

Fig. $2 b$ ) 


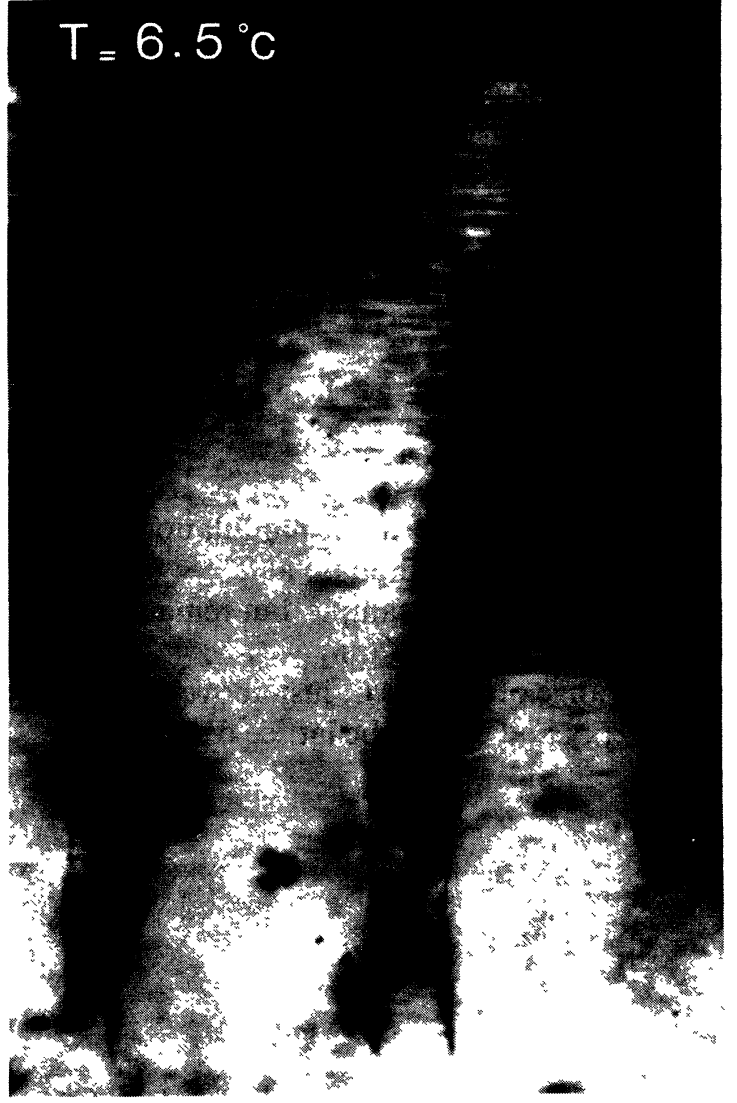

Fig. 2c)

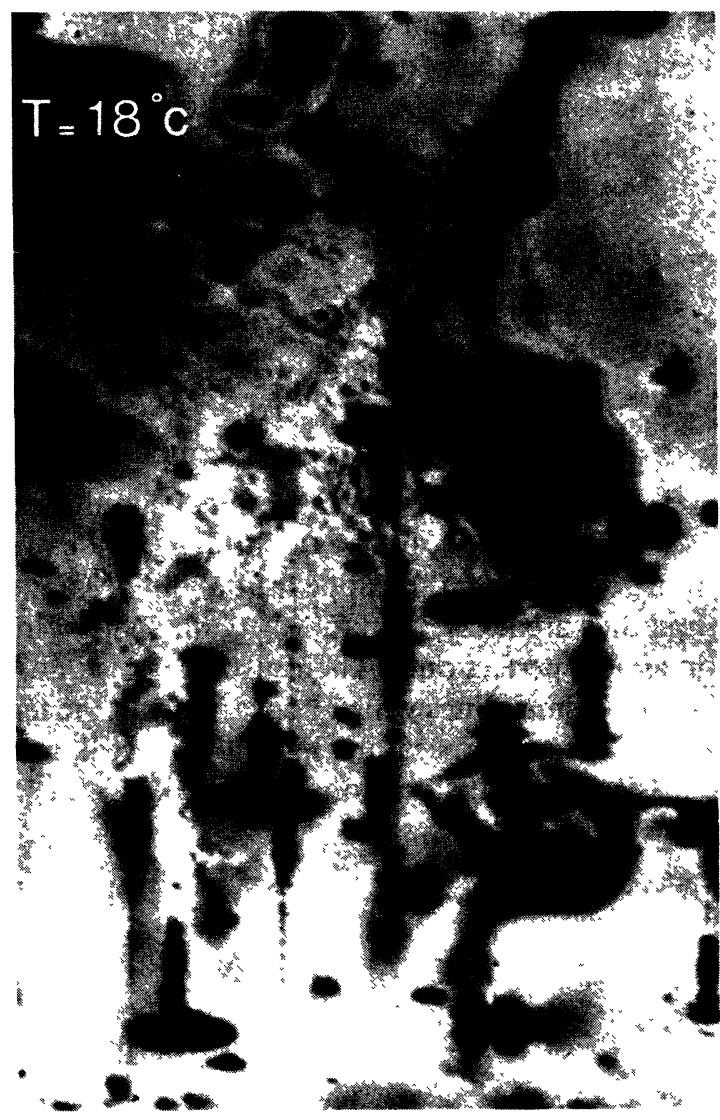

Fig. 2d)

Fig. 2. - Lang X-ray topograph of a (001) slice of $\left[\mathrm{N}\left(\mathrm{CD}_{3}\right)_{4}\right]_{2} \mathrm{ZnCl}_{4} 020$ reflection. a) Topograph of a sample before any thermal cycle - Room temperature; $b$ ) The same sample at $8.3^{\circ} \mathrm{C} ; c$ ) The same sample at $\left.6.5^{\circ} \mathrm{C} ; d\right)$ Topograph of the same sample at room temperature after the first thermal cycle.

In the vicinity of the commensurate phase, the system may be described by a periodic arrangement of discommensurations. The distance between two discommensurations is given by [1] :

$$
\lambda=2 \pi /\left(k_{\mathrm{c}}-k_{\mathrm{i}}\right)
$$

where $k_{\mathrm{c}}$ and $k_{\mathrm{i}}$ are the wave numbers of the commensurate and incommensurate phase respectively.

At a temperature just above $6^{\circ} \mathrm{C}$ the wave vector of the modulation approaches continuously the commensature value of $3 / 7$ [5]. So, the quantity (1) becomes very large and the distance between discommensurations might be of the order of the $\mu \mathrm{m}$. Therefore the estimated period of the small lines measured on the topographs may correspond to a probable density of discommensurations.

So, these defects might be strain field ones associated with discommensuration array or, possibly, decorated discommensurations.

In this case, the weak lines observed on the topographs might be compared to a periodic distribution of mobile defects which would be pinned on large defects in the strained parts of the 
sample (black contrasts), but mobile, so invisible with regard to the observation time, in the good areas (light grey contrasts) of the crystal.

The second kind of defects are local defects : their associated strain fields present two or four lobes.

Two lobe defects could be irradiation defects. But experiments performed on the same slice at a temperature above $20^{\circ} \mathrm{C}$ or below $6^{\circ} \mathrm{C}$ during several days or even weeks under normal experimental conditions for topographics did not produce such defects.

Two and four lobe defects present a line of no contrast perpendicular to the diffraction vector as normally do precipitates. In addition, four lobe defects present a quadratic symmetry. The conditions of weakest contrast are for both of them the same as for dislocations. So, the two kinds of defects could be not only point defect agglomeration, but association of point defects and dislocations. We saw that dislocations are largely decorated during the thermal cycle in the incommensurate phase.

These defects are created during the first thermal cycle, provided that the crystal remains at $8^{\circ}-6^{\circ} \mathrm{C}$ during at least fifteen minutes, so the state of the sample is different for the first cycle and for the following ones. If these defects have any effect on the variation law of incommensurability with temperature, the thermal runs would be sensitive to the thermal history of the sample : this fact has already been observed in $\mathrm{Rb}_{2} \mathrm{ZnCl}_{4}$ crystals [10] in which the variation of the incommensurate parameter is different after repeated heating and cooling runs.

An unanswered question remains : are these defects in the crystal before any thermal cycle, scattered and non resolved by the observation method, or are they created during the first thermal cycle (they might be interstitials or vacancies) ? This last assumption might be justified considering the large number of defects which appear with regard to the excellent quality of the starting crystal.

Moreover, these defects seem to travel along the [100] direction (third kind of contrast). They precipitate when, in their movement, they meet an undersaturated precipitation well (nondecorated dislocation, or small precipitates). So defects are seen to appear and grow: When they are trapped, they become motionless whatever the temperature.

An important point is to understand how these precipitates can move at a temperature far from the melting point. The discommensurations could trap some impurities or point defects but their energy seems too weak to carry such defects over a distance which is of the order of the mm. The movement of precipitates could be allowed by a weak cohesion energy of the lattice, at least in some special directions, in a small temperature range, just above the lock-in phase.

Finally, the long range strains visible on figure $1 b$ which are removed when the crystal reaches the paraelectric phase might be a remembrance of the defect distribution at low temperature, or due to some reordering of the lattice in the incommensurate phase.

\section{Conclusion.}

$\mathrm{X}$-ray diffraction topographies have revealed the existence of new contrasts in the incommensurate phase of $\left[\mathrm{N}\left(\mathrm{CD}_{3}\right)_{4}\right]_{2} \mathrm{ZnCl}_{4}$ crystals.

One of them is pseudo-periodic and disappears in the paraelectric phase. Moreover precipitates are created in the incommensurate phase and remain in the paraelectric phase.

We put forward the hypothesis that the pseudo-periodic contrasts would be associated with a periodic distribution of mobile defects (impurities or point defects) which become again disordered in the paraelectric phase.

The migration of the defects could be either forced by the discommensuration movement or allowed by a weak cohesion of the lattice in a small temperature range above the lock-in temperature. During their displacement, some defects precipitate on wells and they cannot be removed by going into the paraelectric phase.

This interpretation is consistent with the observation via electrical susceptibility or birefringence of a memory effect in other incommensurate compounds. 
The exact determination of the chemical nature of the precipitates, as well as the question of knowing if these defects are created in the thermal cycle or if they pre-exist in the crystal, are now in progress.

\section{Acknowledgments.}

I am grateful to J. P. Jamet for valuable comments and M. Regis for constructive criticism of the manuscript. I am indebted to J. L. Ribet for the supply of very good crystals.

\section{References}

[1] Hamano, K., Ikeda, Y., Fujimoto, T., Ema, K., Hirotsu, S., J. Phys. Soc. Japan 49 (1980) 2278.

[2] JAMet, J. P., LeDerer, P., J. Physique Lett. 44 (1983) L-257.

[3] Errandonea, G., Litzler, A., Savary, H., Toledano, J. C., Schneck, J., Aubree, J., Nato Advanced Study Institute, Multicritical Phenomena, Geilo Norway 10/4-21/4 1983.

[4] Schneck, J., Toledano, J. C., Joffrin, C., Aubree, J., Joukoff, B., Gabelotaud, A., Phys. Rev. B 25 (1982) 1766.

[5] Marion, G., Almairac, R., Lefebvre, J., Ribet, M., J. Phys. C. 14 (1981) 3177.

[6] Marion, G., Almairac, R., Ribet, M., Vettier, C., Steigenberger, U., ILl Annual Report 1982.

[7] LANG, A. R., J. Appl. Phys. 30 (1959) 1748.

[8] Authier, A., Advances in X-ray Analysis, Vol. 10 (Plenum Press, New York) 1967, p. 9.

[9] AuthIER, A., in X-ray Optics, ed. H.-J. Queisser (Springer-Verlag, Berlin-Heidelberg New York) 1977 , p. 168.

[10] Mashiyama, H., Tanisaki, S., Hamano, K., J. Phys. Soc. Japan 51 (1982) 2538. 